\title{
Energy-efficiency networks for SMEs: Learning from the Swedish experience
}

Svetlana Paramonova and Patrik Thollander

\author{
Journal Article
}

\section{Tweet}

N.B.: When citing this work, cite the original article.

Original Publication:

Svetlana Paramonova and Patrik Thollander, Energy-efficiency networks for SMEs: Learning from the Swedish experience, Renewable \&amp; sustainable energy reviews, 2016. 65, pp.295307.

http://dx.doi.org/10.1016/j.rser.2016.06.088

Copyright: Elsevier

http://www.elsevier.com/

Postprint available at: Linköping University Electronic Press

http://urn.kb.se/resolve?urn=urn:nbn:se:liu:diva-132043

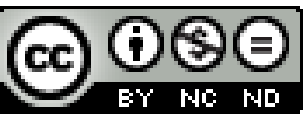




\title{
Energy-efficiency networks for SMEs: Learning from the Swedish experience
}

\author{
Svetlana Paramonova*, Patrik Thollander \\ Department of Management and Engineering, Division of Energy Systems, Linkoping \\ University, SE-581 83 Linkoping, Sweden
}

\begin{abstract}
The potential for energy efficiency improvements in the industry is significant for small and medium-sized enterprises (SMEs), but the implementation of energy-efficiency measures is not always possible owing to various barriers to energy efficiency. Working with energy management personnel inside companies can help to overcome these barriers. However, this is not a common practice among SMEs. Participation in industrial energy-efficiency networks (IEENs) can be a means of introducing customized energy management practices into SMEs. In such a network, industrial companies get support for a period of three to four years from an external network coordinator to determine energy efficiency potential, implement energy-efficiency measures, and monitor energy performance. The method has been used widely in Switzerland and Germany, while in other countries the experience has not proven successful thus far. To show the effects of networking among industrial companies, it is important to evaluate networks quantitatively and qualitatively. This aspect is missing from the field of energy efficiency research, not least with regard to evaluation methods. Thus, it is crucial to evaluate Swedish IEENs and suggest methods for evaluating IEENs. The aim of this study is to review IEENs with particular emphasis on Swedish IEENs. The results show that in Sweden, a common notion of IEENs has not yet been established, and projects with different characteristics and designs fall under the category of IEEN. The lack of a standard approach to running and evaluating IEENs makes it difficult to evaluate Swedish networks quantitatively.
\end{abstract}

Keywords: industrial energy efficiency, energy management, industrial energy efficiency networks, evaluation method, energy efficiency measures.

\section{Introduction}

Industrial processes together with the combustion of fossil fuels contributed about $78 \%$ of the total greenhouse gas emissions to the atmosphere between 1970 and 2010 [1]. Thus, improving energy efficiency in industry is one of the cornerstones of emissions reduction. To this end, the significance of small and medium-sized enterprises (SMEs) has been underestimated historically. However, this trend has been changing, and today, the importance of SMEs from the viewpoint of energy efficiency improvement is recognized [1, 2].

In Sweden, SMEs account for 30\% of industrial energy use [3]. The heterogeneity of the sector makes it quite difficult to find a common approach to work with energy issues. Moreover, energy expenses for a particular company can be quite low, resulting in low interest [4]. A

*Corresponding author: S. Paramonova, mob.: +46760622655, e-mail: svetlana.paramonova@liu.se 
number of studies have focused on investigating barriers to energy efficiency for SMEs [512] and highlighted such barriers as lack of information about energy-efficient opportunities and their costs, high investment, lack of time and other priorities, lack of staff, and insufficient economic incentives and policies.

Another explanation for the low interest in energy efficiency is related to the process of decision-making. Decision-making in companies depends on strategic and cultural factors [13], which explain the differences in the energy-related behaviours of companies with similar conditions. First, investments often need to be strategic or contribute to the 'big picture' to be approved by management. Second, there should be an established energy culture in the organization. Energy-efficiency actions are often not perceived to be strategic owing to the lack of an anchored energy-oriented culture [13]. Moreover, improved energy end-use efficiency cannot be a core competence for a manufacturing company because it does not create revenue [14]. The abovementioned factors explain why energy issues are often not on the everyday agenda in SMEs.

SMEs can possibly supplement their efforts to improve energy efficiency by participating in industrial energy-efficiency networks (IEENs). This method has been widely used in Switzerland and Germany, and it has resulted in improved electrical efficiency and increased investment in energy-efficiency measures $(\operatorname{EEM})[15,16]$. In other countries, however, this concept has not been used as widely. In Sweden, a common notion of IEENs has not been established yet, and projects with different characteristics and designs fall under the category of IEEN. Thus far, a common approach on how IEENs should be organized has been lacking. Good coordination requires an essential knowledge base on running networks, and good competencies, methods, and tools for maintaining effective IEEN performance. To build this knowledge base, quantitative and qualitative research on IEENs in different countries is required. This aspect is missing in the field of energy efficiency research, not least in regard to methods for evaluating IEENs. The important aspects worth studying include not only positive experiences but also challenges related to IEEN performance. Thus, it is crucial to evaluate the Swedish IEENs, as well as to suggest methods for evaluating them.

The aim of this study is to review IEENs with an emphasis on Swedish IEENs. The focus is on SMEs, and therefore, networks for large energy-intensive companies are not considered herein. To present a complete overview of the current situation, the study was divided into two parts: gathering information about existing and completed IEENs for SMEs, and examining their performance. Two maj or research topics were defined (process evaluation and impact evaluation of Swedish energy-efficiency networks for SMEs) with research questions contributing to each topic:

\section{Process evaluation of Swedish energy networks for SMEs}

RQ1: What are the existing and completed energy-efficiency networks for SMEs in Sweden?

RQ2: What are network coordinators' perceptions about energy networks?

RQ3: What are network participants' perceptions about energy networks?

\section{Impact evaluation of Swedish energy-efficiency networks for SMEs}

RQ4: What is the quantitative impact of energy networks for SMEs?

*Corresponding author: S. Paramonova, mob.: +46760622655, e-mail: svetlana.paramonova@liu.se 
The objective is to draw lessons from the current experience and propose suggestions for improvements.

\section{Energy efficiency decision-making in SMEs}

Most often, public policies and programs designed to support industrial SMEs to pursue energy efficiency work are in the form of various types of energy audit programs [17]. The measures suggested by energy audits are reviewed by the company's top management and are prioritized according to the availability of financial and other resources. The measures are usually implemented on a project basis and are often characterized by rather limited implementation of $50 \%$ or lower $[17,16]$. This can be explained by the fact that often energy audits based on economic evaluation do not consider transaction costs and risks intrinsic to longer-lasting investments [15]. Moreover, a focus on the economic perspective alone without considering behavioural aspects does not represent well the complexity of the real world [18].

Decision-making about energy efficiency investments is not solely about making an investment. The process starts from the generation of ideas, diagnosis, building up solutions, and their evaluation. Decision-making is not a linear process and is affected by many internal and external factors at every stage. Among the internal factors are different actors, power relations inside an organization, organizational culture, strategy and management systems, technologies, and infrastructure. External factors include industrial culture, demand and competition, legislation, and public policies [18]. These components must be considered when making decisions. However, the most important issue in terms of improving energy efficiency is making energy a strategic organizational issue. This requires shifting the focus from decision-making grounded in technological-economic thinking to more behaviouroriented approaches. Particular attention should be given to individuals and their views on energy-efficiency actions inside organizations [18]. Another important task in the process of making energy a strategic issue is to shift from project-based energy efficiency activities to more long-term work.

Energy efficiency decision-making among SMEs was investigated by the Alliance to Save Energy [17]. According to one of the findings, industrial representatives thought that energy efficiency ideas are available inside organizations, among engineers and production managers, while advice from peers in the industry is another source of inspiration. Moreover, access to the right source of information can be an obstacle in identifying opportunities because the quality of information from different sources can vary dramatically. It was also proven that SMEs face shortage of time when it comes to training personnel to maintain new equipment [17]. The same holds for Swedish industrial SMEs, where lack of time was by far the highest ranked barrier [9]. These effects of these factors cannot be mitigated by energy audits only. Smaller manufacturers require more guidance, individual support, and implementation assistance [2]. Collaborative activities across companies can help SMEs to implement EEM [1]. Thus, public support in the form of audits should be complemented by programs oriented towards energy management issues and collaboration. Networking across SMEs can be a good platform for energy management and collaborative activities.

*Corresponding author: S. Paramonova, mob.: +46760622655, e-mail: svetlana.paramonova@liu.se 


\section{Networks as a method to improve energy efficiency in SMES}

A network is a group of companies that cooperate with each other to achieve a particular goal, characterized by horizontal and flexible relationships, and mutual engagement [19]. The concept should not be confused with personal relations, association activities, business contacts, and collaboration within agencies [20]. The companies within a network can decrease costs by sharing resources and information, making joint procurement, and reducing administrative work and bureaucracy. Moreover, they can eliminate risks associated with unknown markets and uncertainties. Four types of networking can be distinguished [21, 22], see Figure 1. In the strategic type of networking, the companies themselves choose to participate in networks, which often have an administration and consist of more than two companies.

Cluster
- companies located nearby
(suppliers, service providers,
industrial companies, associated
institutions in a specific field)
(Porter, 2000).
The companies are competitors
but are willing to cooperate.
$\begin{aligned} & \text { Strategic Network } \\ & \text { - a deliberate and long-tem } \\ & \text { network between distinct } \\ & \text { organizations oriented towards } \\ & \text { competitive advantage over } \\ & \text { companies outside the network } \\ & \text { (Jarillo, 1988). } \\ & \text { The companies are willing to } \\ & \text { cooperate and exchange } \\ & \text { information. }\end{aligned}$

\section{Industrial District}

- a geographical and cultural area where employers and workers live and work (Lundberg, 2008; Harrison, 1992) .

The companies are competitors but are willing to cooperate.

\section{Regional Strategic Network}

- a network supported by external actors and focused on companies in a specific geographical area (Lundberg, 2008) .

The companies are willing to cooperate and exchange information.

Figure 1. Types of networking (revised from [21, 22]).

In an energy-efficiency network, companies form a group coordinated by an external actor on a continual basis to exchange knowledge and share experiences about energy efficiency. The coordinator handles administrative functions and leads the work. The companies obtain consultancy from external specialists to gain knowledge about a particular topic (energy efficiency in cross-cutting technologies, motor efficiency, and so on). Thereafter, a mutual goal is defined, and the companies work cooperatively to achieve it. Performance on the network and company levels is monitored constantly. This type of collaboration can help

*Corresponding author: S. Paramonova, mob.: +46760622655, e-mail: svetlana.paramonova@liu.se 
reduce transaction costs, minimize risks, and increase awareness about energy efficiency [23].

Learning energy networks have started to gain attention among industry representatives, policy makers, and energy agencies $[16,1]$, and there is a significant need for research in the field. Some network constituents are well-researched, nationally and internationally, with rather developed methods, tools and standards. These include energy audits [5, 6, 24$26]$ and energy management practices [27-33, 14]. Moreover, several studies on the barriers to energy efficiency in SMEs [34, 7, 35, 4, 9, 10, 12] and energy policies for SMEs [36] have been published. However, there is an obvious research gap in the field of energy efficiency networking and, to the authors' awareness, energy-efficiency networks have been studied only in Switzerland, Germany, and Denmark.

Switzerland was the first successful example with the project Energy Model initiated in 1987 and supported by the Swiss Energy Agency. The participants were exempt from a fossil fuel tax if they reduced their $\mathrm{CO}_{2}$ emissions. Currently, around 70 energy-efficiency networks financed by around 2,000 participating companies exist in Switzerland. The annual average reduction in energy cost achieved by each company is $€ 110,000$ [23]. Encouraged by the Swiss success, Germany established its first network (Energy Table) in 2002. An evaluation of this network showed significant reductions in energy costs and $\mathrm{CO}_{2}$ emissions [23]. The German networking model is referred to as the Learning Energy-Efficiency Network (LEEN). Currently, more than 50 networks operate in Germany, according to the concept presented in Figure 2. The Danish Energy Agency implemented a networking strategy to improve energy efficiency in SMEs. Several energy networks have been established in 100 Danish municipalities, and they represent a platform for the commercial and industrial sectors to work on energy issues with the help of checklists and consultant support [37].

*Corresponding author: S. Paramonova, mob.: +46760622655, e-mail: svetlana.paramonova@liu.se 


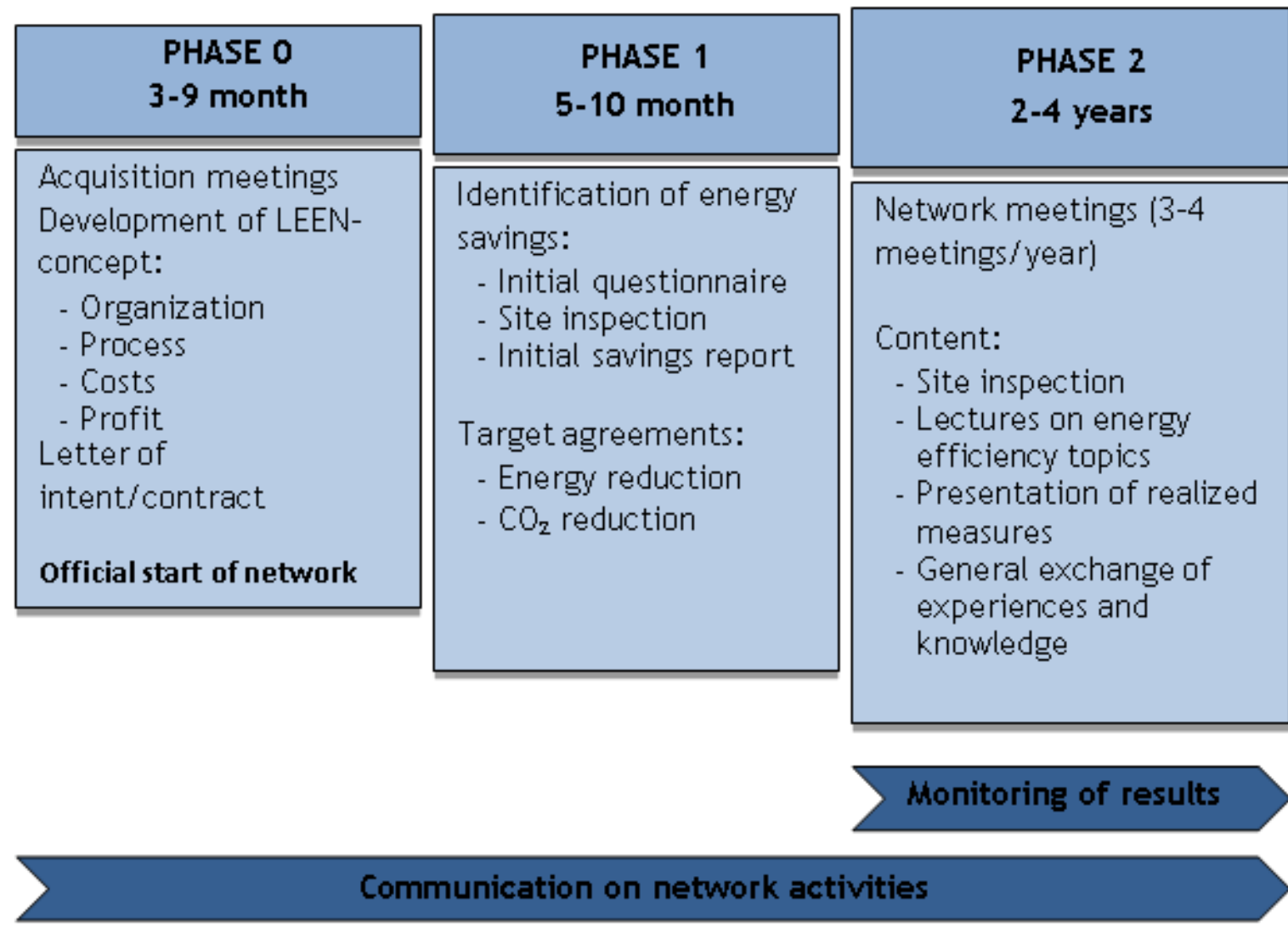

Figure 2. LEEN concept (revised from [38]).

In Sweden, a similar approach (the Hackefors model) has been used since 1996 for joint implementation of environmental management systems (EMS), according to standards ISO 14001 and EMAS [39]. In the Hackefors model, a network is built around a central coordinator who produces documentation, sets legal requirements, creates engagement, and organizes meetings [40, 41]. The participating companies paid a fee for the work of the coordinator. Fifty percent of the costs of staff training, certification, and internal audits were covered by government subsidies [41]. Studies showed that the cost of collaboratively introducing the EMS was half that of doing so individually [41]. Such works can be likened to studies on NGO-farmer partnership in Brazil for agroforestry system design [42], studies on regional actor-networks for sustainable development [43], and a case study of a virtual interorganizational learning network for sustainable production [44].

However, research related to the successful running of industrial energy networks is scarce and is mainly represented by the Swiss and German experiences. Moreover, there are no studies about energy-efficiency networks in SMEs, nor on the challenges related to running energy-efficiency networks. Hence, further research in these particular areas is required. Given that IEENs contribute to an increase in EEM deployment, forming such networks can represent a good strategy for SMEs. Thus, studying the experiences of different countries, both successful and not so successful, is important. The present study representing the Swedish experience in the field of IEENs contributes to establishing the work within energyefficiency networks on a broader level. Moreover, it provides a basis for evaluating IEENs at the country level because such a study has never been performed in other countries. 


\section{Method}

The methodology of this research consists of three distinct parts applied to answer the research questions (Figure 3):

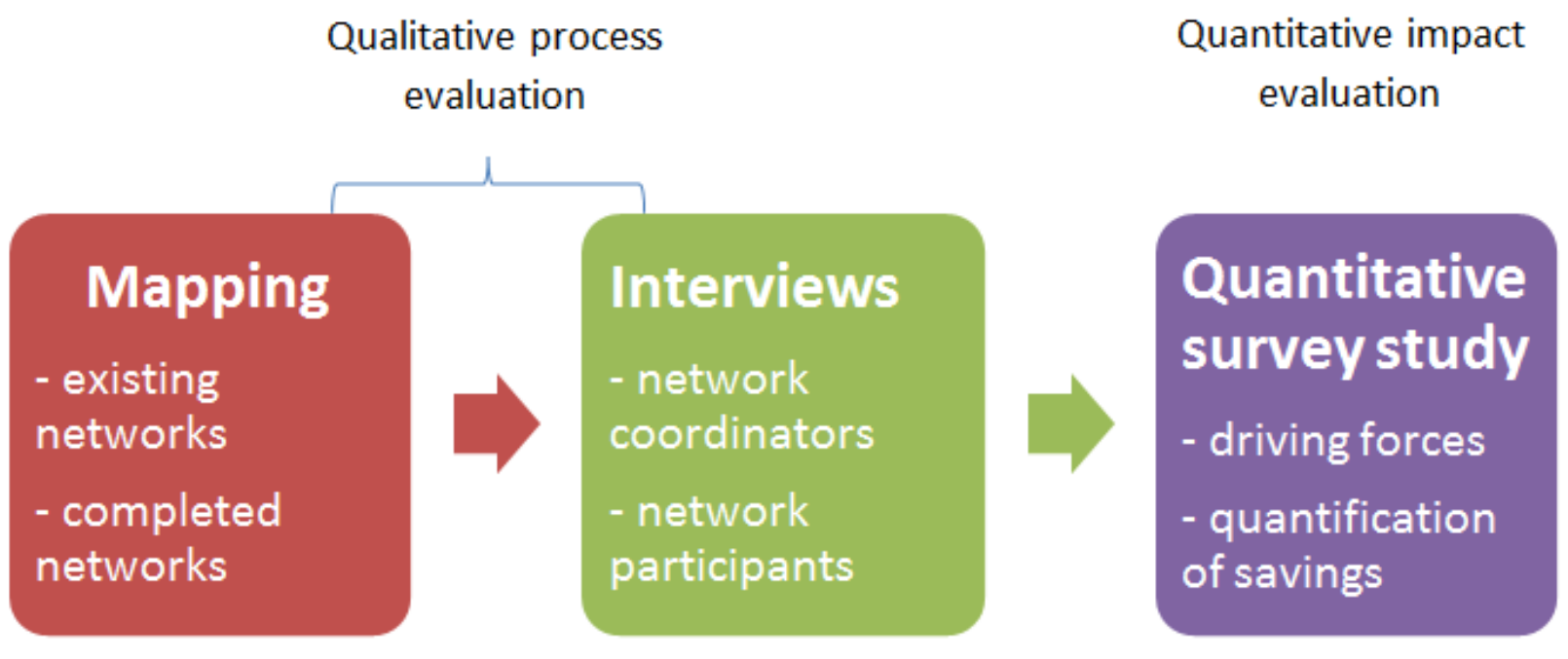

Figure 3. Flowchart of evaluation methodology.

Mapping was done using the 'snowball' method, which involves finding a contact who can refer another contact, similar to a growing snowball [45]. Data collection was started by finding potential coordinators in the public sector (regional energy agencies, county boards), industrial and business organizations, and consulting firms. The Swedish Energy Agency helped identify the majority of the networks. For each network project, the following information was gathered:

- participating companies

- start and finish time

- meetings and their specifics

- participation fee

- availability of contracts

- reported energy use

- industrial sector

- funding methods

- goal and objectives

- underlying reasons for the network project

- activities performed

- monitoring and evaluation results.

*Corresponding author: S. Paramonova, mob.: +46760622655, e-mail: svetlana.paramonova@liu.se 
We conducted qualitative, semi-structured interviews. Owing to the large number of respondents and long distances, interviews with the coordinators were conducted by telephone. However, the network participants were interviewed in person because only ongoing networks were selected for the investigation, which significantly decreased the number of respondents. The study of the coordinators comprised seven interviews. The purpose was twofold: to gather information about the networks' functioning and to obtain the coordinators' subjective opinions about the networks. To obtain the participants' perspectives, we made five visits to network meetings to interview the participants on particular topics. The areas of interview questions for both coordinators and participants are listed in Table 1.

Table 1. Interest areas of interviews (coordinators and participants)

\begin{tabular}{|l|l|}
\hline Network coordinators & Network participants \\
\hline Initiation phase & Reasons to join a network \\
\hline Network goal & Positive experience \\
\hline Organization of networks & Negative experience \\
\hline Activities and management & Possibility for further work \\
\hline Follow up & Possibility for improvements \\
\hline
\end{tabular}

The characteristics of the networks whose coordinators and participants were interviewed are summarized in Table 2.

Table 2. Network characteristics

*Corresponding author: S. Paramonova, mob.: +46760622655, e-mail: svetlana.paramonova@liu.se 


\begin{tabular}{|l|c|c|c|c|c|}
\hline \multicolumn{1}{|c|}{ Network } & $\begin{array}{c}\text { No of } \\
\text { companies }\end{array}$ & Time span & Fee & Contract & Respondent \\
\hline Network A & 9 & $\begin{array}{c}2011- \\
\text { present }\end{array}$ & 300 EUR & n/a & $\begin{array}{c}\text { Coordinator/ } \\
\text { participants }\end{array}$ \\
\hline Network B & 30 & $2011-2013$ & $\begin{array}{c}\text { Government } \\
\text { al support }\end{array}$ & n/a & Coordinator \\
\hline Network C & 8 & $2013-2014$ & Unclear & Agreement & $\begin{array}{c}\text { Coordinator/ } \\
\text { participants }\end{array}$ \\
\hline Network D & $5-10$ & 8 months & $\begin{array}{c}\text { Energy } \\
\text { Agency } \\
\text { support }\end{array}$ & n/a & Coordinator \\
\hline Network E & $6-10$ & 10 months & $\begin{array}{c}\text { Depending } \\
\text { on local } \\
\text { financing }\end{array}$ & $\begin{array}{c}\text { Contract for } \\
\text { attendance }\end{array}$ & Coordinator \\
\hline Network F & $4-8$ & $1-$ several & $\begin{array}{c}\text { Insignificant } \\
\text { fee }\end{array}$ & $\begin{array}{c}\text { Contract or } \\
\text { agreement }\end{array}$ & Coordinator \\
\hline Network G & $4-7$ & 6 months & $\begin{array}{c}\text { Costs for } \\
\text { consultant }\end{array}$ & $\begin{array}{c}\text { Verbal } \\
\text { agreement }\end{array}$ & Coordinator \\
\hline Network H & 4 & $\begin{array}{c}2013- \\
\text { present }\end{array}$ & $\begin{array}{c}1000-4000 \\
\text { EUR }\end{array}$ & $\begin{array}{c}\text { Letter of } \\
\text { intent }\end{array}$ & Participants \\
\hline Network I & 50 & $2011-2014$ & n/a & n/a & Participants \\
\hline Network J & $5-7$ & $2013-2014$ & Unclear & Unclear & Participants \\
\hline
\end{tabular}

The survey study aimed at quantifying the results of work of the Swedish IEEN, and it consisted of two parts. In the first part, the participants were asked to rank driving factors for participation on a scale of 0 to 1 . The following options were available to them:

- 0 -driver is not important at all

- 0.25 - driver is not important

- 0.5 - neutral

- 0.75 - driver is important

- 1 -driver is very important

- 'Do not know'.

The driving forces were categorized into four groups: internal and external drivers, and informational and financial support. In the second part of the survey, the participants were asked to quantify the EEM as a result of participation in terms of kWh saved. The participants obtained a list of EEM categorized according to industrial unit processes: production, lighting, pumping, compressed air system, ventilation, and so on [46]. The participants were also asked to define whether particular energy savings were the result of networking or energy audits performed prior to networking. In total, answers were obtained from 14 companies representing six networks. The first part of the survey was answered by 12 participants, while the second part of the survey was answered by only four participants, which was explained by the participants' inability to define savings in terms of either kWh or money saved.

*Corresponding author: S. Paramonova, mob.: +46760622655, e-mail: svetlana.paramonova@liu.se 


\section{Results}

\subsection{Process evaluation of Swedish energy-efficiency networks}

This part presents the results of the mapping process and the interviews with the network coordinators and participants.

\subsubsection{Mapping of energy-efficiency networks: Swedish experience}

We mapped 32 Swedish network-similar projects in the form of a single energy network or several networks. Two categories of networks were defined: energy-intensive networks (four networks) and networks for SMEs (28 networks). The energy-intensive networks consist of large enterprises with energy use greater than $0.5 \mathrm{TWh} /$ year and financed by the Swedish Energy Agency to the tune of over SEK 2 million for network activities. The networks that do not fit these parameters represent the networks for SMEs. The energy-intensive networks were not considered in our study given our focus on SMEs, but they have been analyzed in a related study [47].

The geographic locations of the identified networks for SMEs are shown in Figure 4. The networks are categorized according to the abovementioned types (Figure 1): cluster (one network), industrial district (one network), strategic (five networks), and regional strategic (14 networks). Networks that did not fit in any of the defined types were placed under the category 'Alternative networks' (seven networks). 


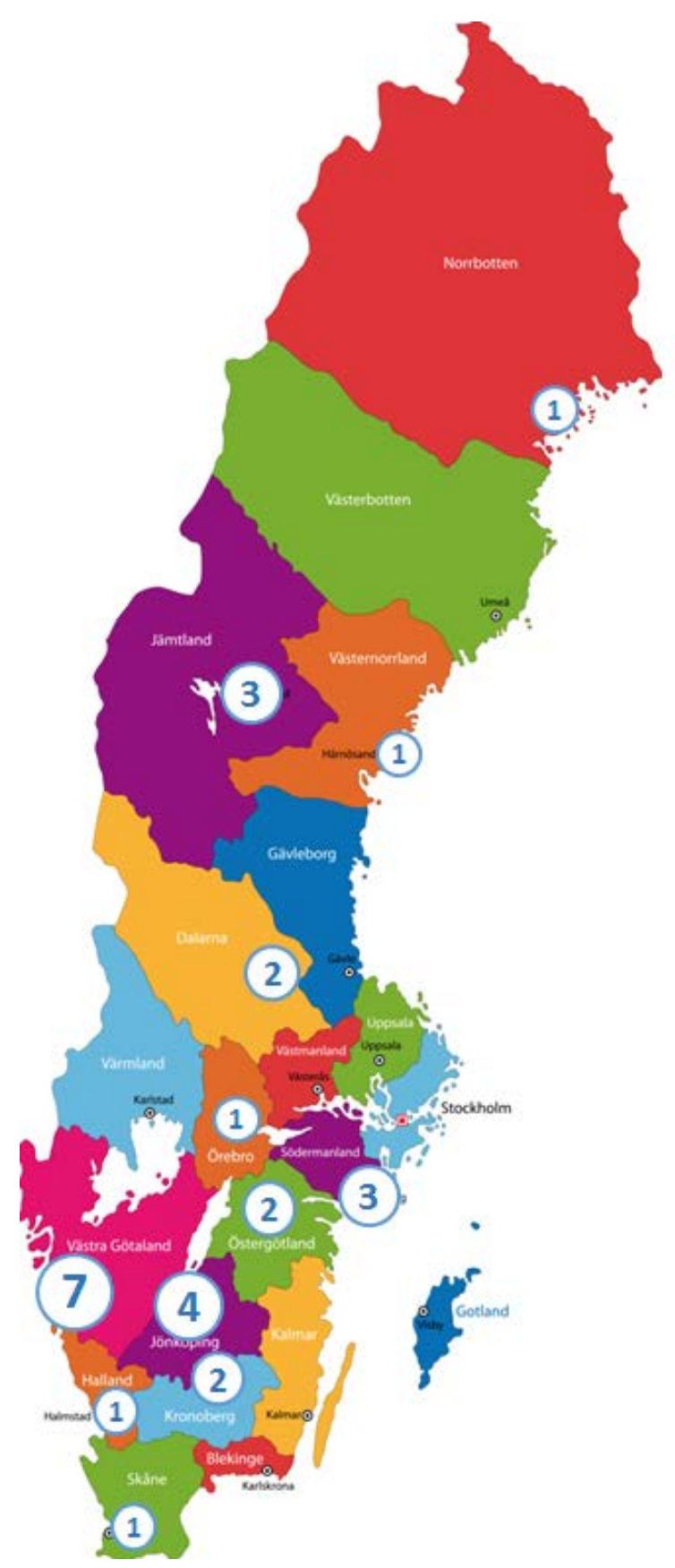

Figure 4. Swedish energy networks for SMEs.

The energy networks differ greatly in character. Administration exists in all networks via a representative from a trade association, regional energy agency, or energy service company. Various levels of ambition owing to levels of knowledge and awareness of energy issues are observed among both the participating companies and the administrative organizations. The administration plays a crucial role and determines the level of engagement. Other important factors for the success of networks are external and internal conditions and availability of resources since they define the extent to which suggested measures are implemented in a network.

Most networks for SMEs are funded by public organizations: The Swedish Energy Agency along with support from the county administrative boards. Other financial resources include

*Corresponding author: S. Paramonova, mob.: +46760622655, e-mail: svetlana.paramonova@liu.se 
regional councils, industrial associations, and the companies themselves. Knowledge and experience exchange take place via meetings. The strategic networks have always had a contract (to ensure attendance at meetings and justify participation in the networks). Internal knowledge varied greatly depending on the participating companies' size and the person involved from the companies. External knowledge is delivered by consultants, who educate participants on particular topics. Energy audits are not a common practice in every network. The companies that perform audits are often supported by the Swedish Energy Audit Program (SEAP). Energy audit practices are more common in the strategic networks because this is often stated in their contracts. Spreading the networking concept was also typical of the strategic networks.

Overall, common energy network activities such as meetings, courses, and study visits take place but not regularly. Lectures and seminars are often given 'as needed'. The short-term effects during networking are participant education and information distribution (about the importance of energy audits in particular). However, the long-term quantified effects are not provided in the final reports owing to the lack of evaluation activities, with some exceptions, when the results of networking are expressed in terms of energy savings. The final reports of the identified networks often lack in-depth descriptions of the activities and final results. This could possibly be attributed to the fact that the projects were not focused on launching networks initially, although their activities resulted in that.

\subsubsection{Evaluation of Swedish energy-efficiency networks}

\section{Coordinator perspective}

This part of the process evaluation aimed to examine the administrative function of the networks.

\section{- Initiative}

The initiative to work with energy issues using networking came from outside (a regional energy agency or energy service company) in seven of the eight cases. In one case, the companies contacted a company that works with business development in their county [48]. The required number of companies was obtained via business associations, chambers of commerce, informational workshops, industrial cooperation, and municipal channels. The coordinators believe that it is easier to build a network using existing connections: industry or local cooperation. Networks based on geographic proximity and sector-specific networks have advantages and disadvantages. Companies from the same sector have more in common to share. However, competition can limit the information shared. Companies located in the same area may not have much in common. However, they can arrange informal visits. Certification according to standards such as ISO 14,001 and ISO 50,001 can be useful to get the companies used to a structured way of work and to apply standard procedures when working with energy. Furthermore, adoption of standards highlights the companies' environmental ambitions.

- Objectives and goals

*Corresponding author: S. Paramonova, mob.: +46760622655, e-mail: svetlana.paramonova@liu.se 
The goals mentioned most often were increasing and sharing knowledge and experience, and mutually procuring energy services to minimize costs. However, not all networks defined goals. One coordinator argued that the participants did not have a clear understanding of networking, what they expected, and what was expected of them. The regional energy agencies often set more general goals to facilitate climate and energy strategies on the municipal or county level. In such cases, the goals mentioned most frequently were national and EU climate and energy commitments, the 20-20-20 target [49-52].

\section{- Organization of networks}

\section{Participants}

The number of companies in the networks can vary, but the optimal number of participants mentioned is around ten companies. If there are too many participants, not everyone can participate in discussions, but having too few participants might lead to less fruitful discussions [53, 50]. This is also aggravated if some companies skip meetings or leave the network because of other priorities [52]. The company representatives often had different occupational positions, but they continued to represent their companies throughout the network's lifespan. It is very important to be able to deliver the message to the rest of the company. Moreover, it can be hard to achieve a positive result if the network participants and top management have different motivations [52]. Participation by top management can raise interest within the companies and inside the networks [53].

\section{Lifespan}

Three networks were operating on a project basis for 6-10 months, while the rest for one to several years. The coordinators' opinions about how long a network should last differed. One coordinator stated that six months can be enough to obtain results, and a network can be extended if needed [53]. Several coordinators mentioned that project specificity determines network lifespan [49, 51]. Furthermore, it was mentioned that networking should continue as long as the companies are interested and as long as there are positive outcomes [48].

\section{Costs and contracts}

Some coordinators thought a network fee is a good motivation to work further with implementation of EEM [49, 52]. In one example, a network first subsidized by the Swedish Energy Agency created an association with a membership fee when it became mature enough [51]. A contract can be a means to ensure attendance at meetings and commitment. Some networks use informal rather than legal agreements: letters of intent that can be changed according to the companies' needs [51].

\section{- Activities and management}

\section{Activities and structural organization}

Most networks did not have a structured organization with defined phases, nor did they have a common approach to how the companies should commit themselves to work. One network was initiated based on a lecture by an external expert on how to perform an energy audit and how to work with improved energy efficiency. Another coordinator stated that energy audits were difficult to perform owing to the differences between the companies, and thus,

*Corresponding author: S. Paramonova, mob.: +46760622655, e-mail: svetlana.paramonova@liu.se 
a simplified paper template was used to register energy use. The companies could use the experience of external consultants provided by the Swedish Energy Agency or recruited by the companies themselves [49]. Another coordinator mentioned that the idea of conducting energy audits was not realized owing to the lack of pressure from the coordinator. In the second network, the companies implemented the lessons learned and performed energy audits with the help of an external consultant. In four other networks, energy audits were routine. One network created a database of energy audit results [51]. The database can be used by companies unable or unwilling to conduct audits. Checklists for energy audits were also provided by regional energy agencies.

In one network, the companies were helped by the network's administration in implementing the measures suggested in energy audits. In another network, the companies could contact the county board about possibilities of getting grant to implement recommended measures [52]. However, most frequently, the companies chose which measures to implement depending on what they had time for. In two networks, measuring energy use was a necessary part of the energy audits to ensure transparency of the results [48, 50].

Activities common to all networks were regular meetings hosted at the companies, facility visits, and theoretical sessions. One network had a rather defined structure. First, the companies were educated to define internal energy use. Once a month, they met to track each other's performance. At the meetings, they had technical lectures and energy-related key performance indicators (KPIs) were presented. Every company made a plan of what to do for the next meeting, and these plans were reviewed at the next meeting and controlled by measurements. The companies discussed how to solve particular problems and then applied the lessons learned. After some time, everyone started doing something related to improving energy efficiency [50].

\section{Coordinator's role}

Almost all interviewees mentioned the decisive importance of the networking coordinators in holding the companies together. One coordinator expressed doubts about the SMEs' ability to work with energy questions without networking because they are not aware of their potential to improve energy efficiency [54]. The companies within one network tried to continue meeting after the end of the project. However, after the third meeting, attendance was only $5 \%[50]$.

\section{Consultant's role}

There is a big difference in the skills of energy consultants, according to the interviewees, which affects the success of networking. There is also the risk that the companies rely entirely on the consultants' word [51]. After implementing the proposed measures, the companies may think they have done everything possible and miss some opportunities. The Swedish energy efficiency consulting sector needs to mature, and there is a lack of standards in this area [51]. Recommendations from colleagues who have worked with skilled consultants and a list of good-quality consultants can help in this regard. Furthermore, good consultants need to be able to communicate the results of their work, form good relationships with the companies, and motivate them [52]. This has been proven in research related to the outcomes of industrial energy audits [55].

*Corresponding author: S. Paramonova, mob.: +46760622655, e-mail: svetlana.paramonova@liu.se 
- Follow-up

None of the networks have had sufficient follow-up procedures. According to one coordinator, initially, there were requirements for follow-up of the results. However, it was hard to perform [49]. This can possibly be ascribed to the setting of broad and difficult-tomeasure goals (e.g., '20\% reduction in energy use') [50]. One coordinator mentioned that the goal of $20 \%$ reduction in energy use was too ambitious for their network [51]. Several companies also mentioned the difficulties in measuring energy efficiency owing to variations in production, product profile, and the market $[50,53]$.

\section{Participants' perspective}

This part of the paper presents the perspective of the network participants.

\section{- Reasons for joining an energy network}

The most common reason for joining a network was to decrease energy costs. One company with old premises and significant heat losses wanted to discuss with peers how they solve similar problems. Another company from the same network paid too much in energy costs and wanted to look at opportunities to improve their heating system. Owing to the lack of time, they decided to rely on the consultant provided by the network [56]. One company from another network attended a seminar where networking was promoted, which inspired to the company to join in order to reduce its energy costs. The company expected to get help with energy audit and implementation of suggested measures [57].

Another often-mentioned reason is interest in energy questions from the top management. In one case, top management promoted energy questions within the company. The company implemented EEM in different areas (LED lighting, heat pump installation, and so on). However, after implemented the easy measures, the company realized the need for external help [58]. The top manager of another company was interested in energy issues but needed help to find areas for improvement. They wanted to install solar collectors, but it lacked the relevant information. When they saw an advertisement in a local newspaper, they applied for participation [57]. A company in another network had also done a lot of work on saving energy (improving ventilation and lighting systems) and wanted to know what more they could do. This company got a little bit more analysis and attention in the project because they were ahead in the process [59].

One more reason for joining a network was to establish energy efficiency work in organizations. One company said that they were interested in work on continuous improvements; however, they did not have too many expectations from networking because it was a new concept. Another company's manager said that they needed motivation to launch continuous work with energy through external help.

\section{- What worked well during networking?}

Networking helped the companies to plan how to decrease their energy use. A manager from one company said that an energy audit proved what they had already found and showed them how to work further. They started to register trends in annual oil and electricity use

*Corresponding author: S. Paramonova, mob.: +46760622655, e-mail: svetlana.paramonova@liu.se 
going back four years, which helped them see where potential for savings can be found [56]. Many companies realized the extent of their energy loss after participating in a network. They learned how to run production equipment more efficiently, without losing energy during machine shutdown, for example.

The participants mentioned that networking helped them to set goals and KPIs for further work. Since all the networking participants are aware of the others' goals, it helps to not stop working. Not every company used quantified goals; some of them had the goal "to optimize as much as possible and to implement as many measures as possible" [56]. According to one participant, performing an energy audit was necessary to understand where to look for improvements, but the network was an inspiration to do something and understand where to start. It also helped to set a deadline. According to another participant, networking helps in the decision-making process by placing priority on the measures. His colleague added that an energy audit is not a guarantee for implementation of measures, but a networking engagement ensures that some measures are realized.

One participant said that networking is valuable because of other participants' feedback on the work performed. This motivated them to implement all the improvement recommendations they had received [57]. Visiting other participants' facilities was useful to understand what peers do, in addition to acting as a source of inspiration [59]. A good circumstance is the difference between participants: different potentials and different levels of success in energy efficiency work can help sustain motivation among group participants who did less of such work.

Moreover, networking raises energy awareness among staff. A manager from one company mentioned that the networking activity helped to realize the importance of behavioural aspects for lighting, for example. Several persons claimed that their employees became interested in contributing to the mutual work. Knowing that their company is involved in a project to minimize energy use, the employees started to work in a more disciplined manner [56]. According to one manager, networking helped to introduce energy-related aspects in weekly meeting agendas [57]. It took quite a long time for this company to start working on with energy issues. However, the issues received increasing levels of attention and with time, and staff discipline increased gradually.

\section{- What did not work well during networking?}

Many companies mentioned that they did not have enough time and staff resources to work continuously, even though individuals could be very ambitious. This is because they operate multiple projects in parallel. This pertains not only to the implementation of measures but also to participation in network meetings. Problems can also arise when a company has to measure energy use in their premises. For example, in one network, one company had a problem with measuring energy use, and they preferred to use theoretical calculations.

Different levels of engagement can be seen when comparing various participants' achievements. While some participants start work immediately, others within the same network take a long time. The explanation is insecurity about the pay-off of the measures and difficulties prioritizing among EEM.

*Corresponding author: S. Paramonova, mob.: +46760622655, e-mail: svetlana.paramonova@liu.se 
In addition, there were negative responses about the networking experience. One company said that the networking took too much time and did not give them anything in return. Instead, they were visited by a company selling ventilation equipment proposing to buy a new fan instead of making relevant suggestions. They joined the network because they were inspired by the introductory lecture, but the participation did not fulfil their expectations. Another company from the same network stated that they did not get any support during the project. They were divided in different groups, and there was no learning atmosphere or unity in their group. They would have liked to contribute to group learning, but they did not see any interest from the rest. In contrast, in another group with higher levels of participant ambition, the results were very positive.

\section{- Further work after a network ends}

The maj ority of the interviewed companies would like to continue work on energy issues by means of networking. One reason is that not all the EEMs were detected during networking and there remains considerable potential for improvement. One company said that it is interesting to continue to see where this work would lead other participants. Several respondents mentioned that they would have continued in a better-organized network. One participant stated that other groups from their network were given more attention by the coordination side.

In terms of the participation fee, several participants were willing to pay it because the issue is very important to them. A fee is expected when work is coordinated professionally. However, they found it hard to decide how much they are willing to pay. Others opined that paying for the kind of network they were involved in would not be worth it.

There are many ways to improve the existing networks according to the companies. First, it is very important to set goals, mutual and individual, to follow the performance of the companies and motivate them. The interviewed companies mentioned that they want to see the result of networking, which is not possible without quantified goals.

The quality of the consultants' work should be ensured by the network administration. The participating companies expect to hear good reasoning that they can rely on. When they do not get answers to their questions, their participation comes into question. They also should be able to understand what is expected from them, as well as the measures they are suggested to implement. The suggestions should be clear and concrete in order to save time. Moreover, more external knowledge should be disseminated by the energy advisers. One participant said that after some time, their network depleted the entire potential, and it was difficult to find new ideas, which, in this case, should have come from outside their company.

Another suggestion was to make the network meetings less theoretical and more adapted to the respective participants' needs. Concrete technical and practical questions are more interesting to discuss according to the participants.

\subsection{Impact evaluation of the Swedish energy-efficiency networks}

This part aims to investigate the drivers to join learning energy-efficiency networks, as well as to quantify energy savings due to enrolment in them.

*Corresponding author: S. Paramonova, mob.: +46760622655, e-mail: svetlana.paramonova@liu.se 


\subsubsection{What was the main motive behind engaging an IEEN?}

In this part, the main drivers to join an IEEN as ranked by the network participants are presented.

The most important driving force mentioned by the companies was cost reduction resulting from lower energy use, ranked 0.9 on average (Figure 5). This factor was ranked as very important in ten cases and as important in one case. This is followed by threat of rising energy prices $(0.81)$, commitment from top management $(0.71)$, energy advice from seminars (0.7), government-advised energy audit programs (0.69), people with real ambitions (0.69), energy taxes (0.68), and long-term strategy $(0.67)$.

The factors that had the lowest ranking were European Emission Trading System (0.23) and pressure from the public sector and environmental organizations $(0.25)$.

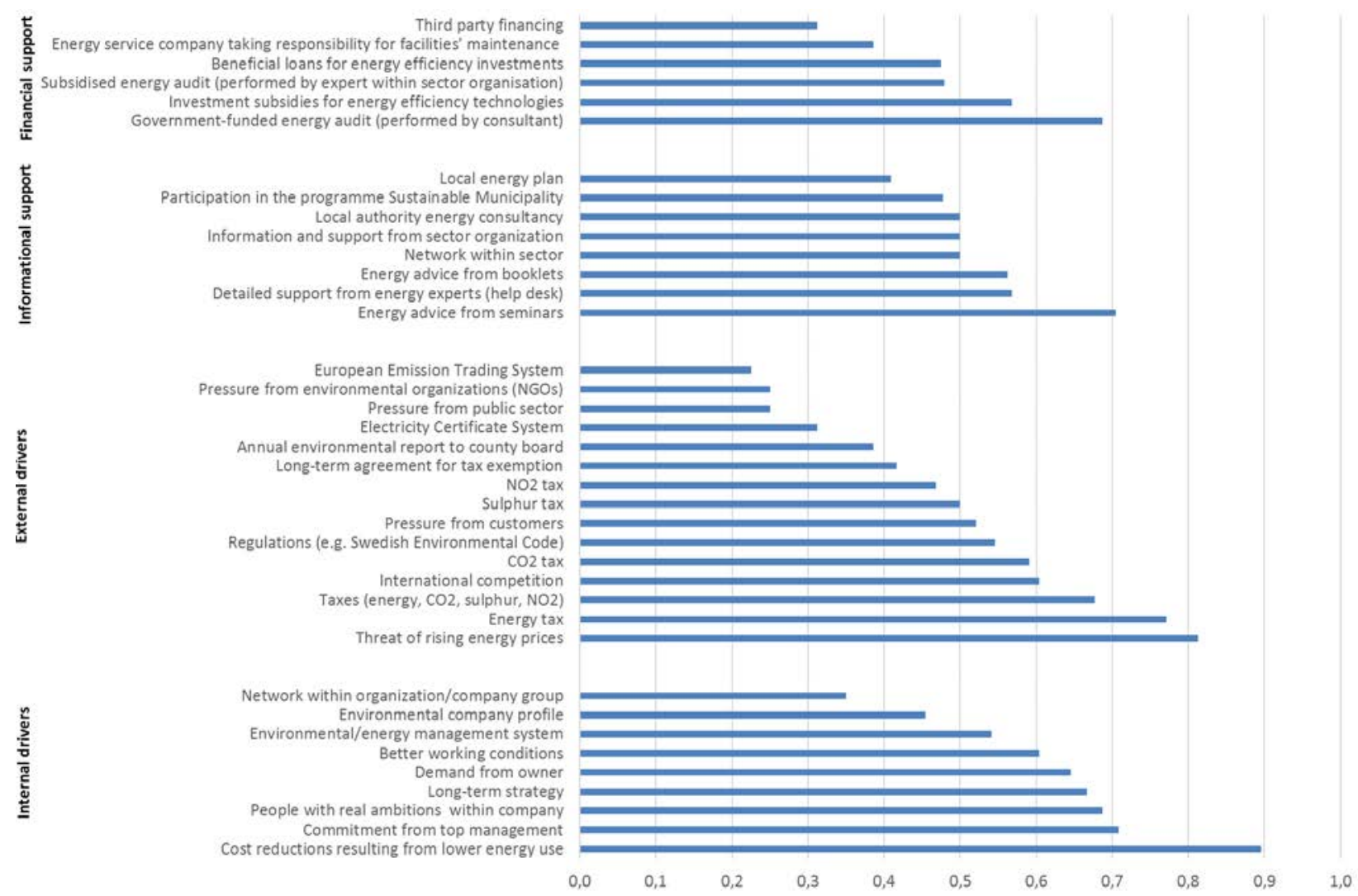

Figure 5: Driving forces to join the energy networks from survey study.

\subsubsection{Quantitative evaluation}

The results of the questionnaire for quantitative estimation of savings potential resulting from networking cannot be used for impact evaluation because the majority of the companies surveyed could not provide any numbers about the energy they have saved owing to the EEM proposed during the networking. This could possibly be attributed to the fact that the evaluation procedure was not a necessary part of the network structure. Thus, this part does not provide any generalizable quantitative results, but instead gives four specific examples. The answers were obtained from four companies: a specialized machinery

*Corresponding author: S. Paramonova, mob.: +46760622655, e-mail: svetlana.paramonova@liu.se 
manufacturer, manufacturer of control systems, food products company, and glass manufacturer.

The specialized machinery manufacturing company found additional energy efficiency potential in five areas related to heating systems: insulation of building shell, temperature decrease, change of windows, reducing infiltration through walls, and use of excess heat from processes. The total energy saving in the form of heat owing to these measures was $350 \mathrm{MWh}$, in addition to an energy audit.

The company producing control systems found an EEM in the heating system (temperature decrease, reducing infiltration through walls) equivalent to $20 \mathrm{MWh}$ in heat savings from district heating and $4 \mathrm{MWh}$ in electricity savings. Additionally, $1.5 \mathrm{MWh}$ of electricity was saved as a result of time-control of the ventilation system.

The result of networking for the food product company was an EEM suggested for the heating system (use of excess heat, control of heating system); time-control of the ventilation system; an EEM related to lighting, for example, the use of energy-efficient fixtures and change in behaviour; and as EEM in the production processes (control systems and process optimization). The respondent did not report energy savings in kWh but mentioned that the heating measures resulted in $5 \%$ electricity savings and $5 \%$ fossil fuel savings, and both the ventilation and the lighting measures resulted in 5\% electricity savings. The measures implemented in the production processes contributed to $10 \%$ electricity savings and $15 \%$ fossil fuel savings.

The glass manufacturing company could not provide quantified information about EEM through networking and only reported that in addition to an energy audit, a few additional improvements were suggested, including reducing infiltration through walls and use of excess heat.

\section{Discussion}

\section{Current status of energy networks in Sweden}

The concept of IEENs in Sweden has not been developed to nearly the same extent as in Switzerland and Germany. The difference between Switzerland and Sweden can partly be explained by the lack of a national joint effort. The Swiss networks are part of a national policy, while the Swedish networks are local initiatives without tax exemption. With regard to the German networks, around 30 of them were founded by one German company. Many of the Swedish networks presented in this paper have been formed as projects without common framing and they differ in form. However, these different types of networks are similar in the resources required to conduct them. Administration is part of all projects, although its magnitude varies significantly. The origin of the coordinating organization does not affect any network's success, and there is no evidence that the regional energy agencies work in a more structured way than the energy service companies. It is easier to build a network on an existing management system from the viewpoints of reducing administrative burden and enhancing the skills required to work in a standardized manner. However, the availability of management systems should not be a requirement. There is a need for a structural approach during networking, which was lacking in all networks.

*Corresponding author: S. Paramonova, mob.: +46760622655, e-mail: svetlana.paramonova@liu.se 
All networks received financial support from the public sector. However, coordinators and participants agreed that some sort of fee can be levied to ensure engagement and commitment to participate in meetings and implement EEM. At this stage of energy network development in Sweden, it seems important that the government implement a national support scheme because it can be quite difficult to make companies pay for a network scheme that is not well known. When the networks mature, they can be financed by the participants. In the networks that stipulate some sort of contract, there is a higher chance of implementation of the suggested measures. Thus, it is recommended that the participating companies sign an agreement committing to implement the proposed actions. One potential future direction for Swedish networks could be to offer a tax exemption, as is the case in Switzerland.

In terms of external expertise, the level of experts' knowledge can vary considerably. This can be avoided by good network administration, since knowledge and experience exchange among participants minimizes the risk of using consultants with inadequate service quality.

Currently, it seems problematic to follow up on network activities in Sweden. It is difficult to determine how well they work and what they result in owing to insufficient information. Most of the final reports did not provide information on the overall performance, based on which to discern the impact of the energy networks. Only a few networks partially reported their performance. In most cases, it was only stated that information and knowledge were shared among the participants. Neither the participants nor the coordinators provided solid information in this regard. Only individual participants with good results have been highlighted in the study, and these accomplishments cannot be evaluated quantitatively to any extent.

Engagement among participants has been argued to be very important for network success by both the coordinators and the participating companies. Moreover, a network with common activities is by itself a platform for initiating engagement among companies. Our interviews with the coordinators showed that activities such as meetings, external lectures, seminars, and company visits work very well. There is a correlation between the level of success of a network and the number of structured meetings conducted in the network. The effectiveness of meetings depends on the number of participants, which should ideally be around 10 to ensure a healthy level of discussion. It is important that the participants understand the reasons behind their network and the activities carried out by it. The presence of personnel from a company's management team can, at least occasionally, raise interest among the members of said company, as well as in other companies. This can also increase the commitment to implement proposed EEM.

\section{Advantages of participating in IEENs}

In general, the interest in creating energy-efficiency networks from the companies' and municipalities' side is quite strong. The majority of the networks have the 20-20-20 climate and energy targets as their goal, which is explained by the fact that the municipalities perceive networking as a contribution to the EU climate strategy. The majority of the participants see networking as a way to reduce energy costs by means of learning and experience exchange. The companies' interest in the networks is confirmed by their willingness to continue meeting after the end of the projects. Energy audits help define areas for improvement, while networking helps understand how to further work on the *Corresponding author: S. Paramonova, mob.: +46760622655, e-mail: svetlana.paramonova@liu.se 
suggested areas. When sharing experiences with peers, new possible solutions arise, especially if there are many ambitious and successful examples within a network. The companies consider networks as a source of inspiration in their energy work. Thus, networking can be a way to increase the level of implementation of EEM and to shift the focus away from implementing only short-term measures.

The second highest-ranked driving force to join networks was commitment from the top management, as confirmed by the interviews with coordinators and participants. Many of the companies joined networks owing to the initiative of their respective top managements. However, more importantly, participation in energy networks helped spread awareness further among the personnel, as mentioned by many companies.

Lack of time and resources are considered decisive obstacles for SMEs to perform energy efficiency actions on an everyday basis. Establishing continuous energy work in the form of energy management systems in SMEs is often hindered because this process requires commitment. By means of participating in an IEEN, the companies partly outsource energy management activities to the administration. In this way, energy-related work can be adapted to a specific company and external conditions (energy prices, taxes, economic conditions) and is thus sustained. It then becomes a necessary part of company strategy and can be anchored in corporate culture. Thus, not only people with energy-saving ambitions would determine the company's approach to dealing with energy but also energy saving in itself would be considered a part of the decision-making process in companies.

When companies get to know how great their potential to save energy is and how to achieve it, when they share knowledge and experience, learn from each other, and obtain information from external experts, the effects of informational and behavioural barriers can decrease. Mutual learning within an energy network thus contributes to learning within the participating companies. The administrative burden and risks are shared, while transaction costs are minimized, as also mentioned in [60].

\section{Improving networking}

Participating in an IEEN alone cannot guarantee improved energy efficiency. To bring about positive results, a network should be designed and managed properly. In relation to the more mature Swiss and German networks, the Swedish networks need to be developed in several respects.

The main finding is that a network must have a driving force in the form of a coordinating organization. The coordinating organization plays the role of the engine that drives work, organizes meetings, invites external experts, and creates engagement on the network level. That the success of a network depends considerably on the network's governance is supported by international research as well $[41,23]$. Moreover, continuity plays a key role because the network's work follows the definite cycle of mapping, planning, follow-up, and new measures. Systematic work leads to changes in organizational behaviour, and when supported by administrative procedures, it can contribute to measurable results. In this way, SMEs can place administrative burden on the coordinating organization.

The administration of networks needs time and funding, but is necessary to structure the work by dividing it in stages and reporting the effects of the stages. Common procedures for

*Corresponding author: S. Paramonova, mob.: +46760622655, e-mail: svetlana.paramonova@liu.se 
network coordination are the most important parameters for effective networking, together with the monitoring of networking activities and performance measurement [61]. Thus, the most important thing is to adopt a structured approach to running energy-efficiency networks. Hence, there is a need for network models that guide participants through the various phases in the networking process. However, there is always a risk that the administrative system becomes a paper burden, where following procedures is prioritized over actual actions. Thus, networking can only be effective if the underlying administrative procedures are simplified and adapted to the users, rather than following a strict pattern.

The other areas for improvement are proper goal-setting and establishing follow-up procedures. Energy networks result in higher levels of EEM implementation if their goals are defined clearly. The networks whose objectives are formulated in more general terms such as spreading information and developing energy efficiency skills have less chance for success. There should be a common goal for the entire network, as well as individual goals communicated internally and externally to the network. The 20-20-20 energy and climate target seems to be rather vague for the participants, and the goal should be expressed as a specific energy use reduction ( $\mathrm{kWh} /$ product, for instance) or a number of EEMs. The use of KPIs can help cope with differences in production. Moreover, this would facilitate evaluation of network performance and define energy savings.

The follow-up procedures should be determined on the network level. It is strongly recommended that future networks be clearer in reporting performance, as well as what has worked and what has not worked well. Preferably, all implemented activities should be measured. Demonstrating the effects of participation can elicit greater commitment and more fruitful knowledge and experience exchange because tangible results are easier to communicate among the participants.

Moreover, there is a need for better-qualified energy auditors and experts, which may be achieved by way of certification. The quality of energy consultants' work should be approved on the network level, and a list of good energy consultants should be available to the network members in order to secure a good level of the proposed EEM.

\section{Conclusion}

SMEs often lack the resources necessary to work on energy issues, and energy issues are rarely a part of their strategy. Thus, SMEs require public support to engage in energyefficiency activities. However, public programs that only subsidize energy audits seem insufficient in this regard, and the implementation of measures proposed in energy audits should be supported by networking. The results of this paper show that participating in IEENs and outsourcing energy management practices to network administration help SMEs overcome typical energy efficiency barriers such as lack of resources and insufficient information. Network participants can get information about available solutions from their peers and eliminate many risks related to technology implementation. Moreover, participating in energy-efficiency networks can shift companies' attention from technoeconomic aspects of energy efficiency to behavioural aspects. IEENs can contribute towards changing attitudes and behaviour by allowing companies to learn from their own and others' experiences.

*Corresponding author: S. Paramonova, mob.: +46760622655, e-mail: svetlana.paramonova@liu.se 
Figure 6 shows a general model for understanding energy-efficiency networks. As shown in the model, the full potential for energy-efficiency networks not only involves technology diffusion, mostly covered by energy audits, but also improvements related to energy management procedures. Moreover, networking increases the rate of implementation of the EEMs proposed in audits. This general model provides an enhanced theoretical understanding of the usefulness of energy-efficiency networks as an energy policy towards industrial SMEs.

\section{Energy efficiency potential for energy-efficiency networks}

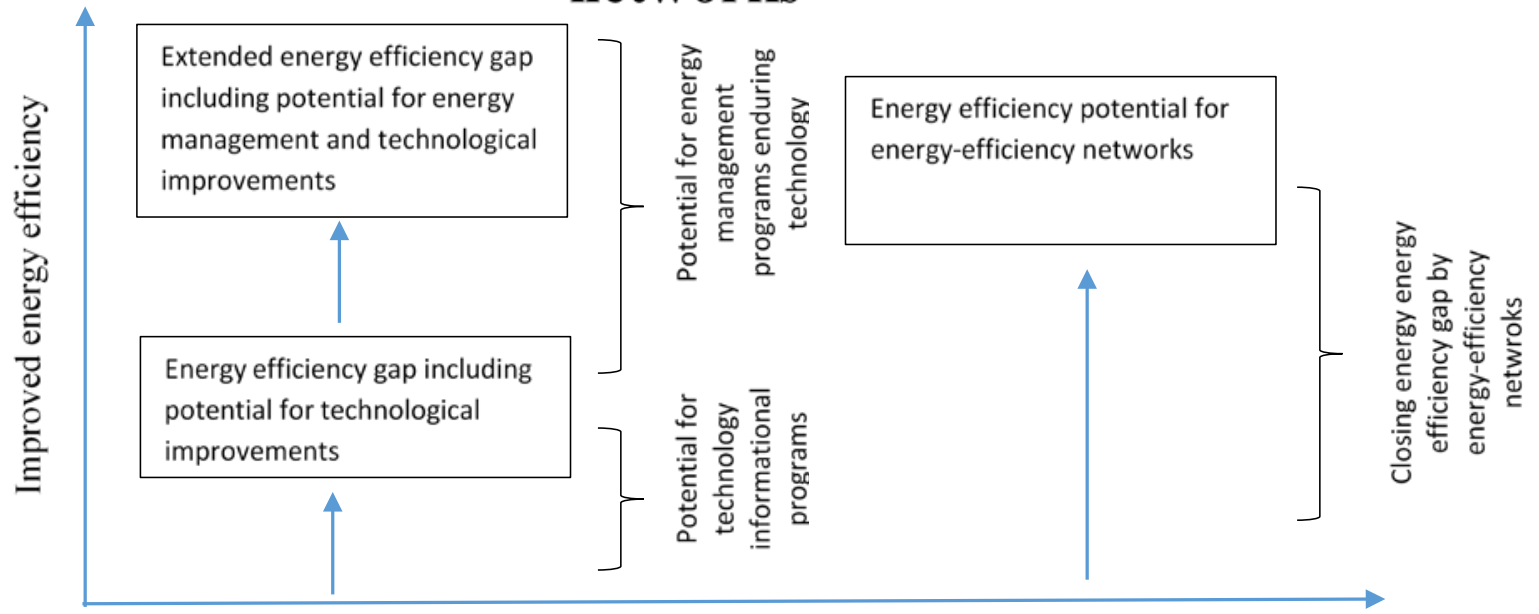

Baseline $\mathrm{BaU}$ (Business as Usual)

Figure 6: General model of energy efficiency potential for energy-efficiency networks (inspired by [62]).

The findings presented in this paper based on a review of the scientific literature on IEENs in general, and Swedish IEENs in particular, contribute to the international knowledge on IEENs, which, to the authors' awareness, has mainly been represented by the Swiss and German examples thus far. The concept of IEENs in Sweden is not yet developed to the same extent as in Switzerland and Germany, and it lacks a common structure or frame. Many of the networks in Sweden were developed as projects and are different in form. One possible reason is that many of the IEENs were started with another aim, resulting eventually in energy networking. At present, it is not possible to quantitatively evaluate the network activities in Sweden in terms of energy or money saved, how well they work, and what they result in owing to insufficient information. Most of the final reports reviewed herein did not provide information on the overall network performance and where the impact can be discerned, and only a few of the energy networks' provided partial performance reports. In the majority of cases, the results were presented as statements that information and knowledge have been shared among the participants. Further information could not be provided by either the coordinators or the participants, and only individual participants with good results have been highlighted in the study without the possibility to be evaluated quantitatively to any extent.

Similar studies of IEENs in different countries are required to build a knowledge base of methods, tools, and good competencies, as well as for maintaining effective IEEN *Corresponding author: S. Paramonova, mob.: +46760622655, e-mail: svetlana.paramonova@liu.se 
performance. Both positive experiences and challenges arising in IEENs should be studied. Thus far, such studies are missing in the domain, not least in regard to methods for evaluating IEEN. The methodology proposed in this paper is recommended for consideration by similar international studies. It is important to perform both qualitative and quantitative evaluation. The qualitative part should consist of the network mapping process and investigation of coordinators' and participants' experiences of networking. While coordinators should be examined on such matters as network organization and management, it is important to investigate participants' positive and negative experiences, and expectations. Further, quantitative investigation in the form of surveys or interviews with both coordinators and participants should follow to evaluate network performance in terms of energy and money saved. In this study, the last part was not possible simply due to the lack of quantifiable data. Thus, we recommend that follow-up procedures should be determined from the outset on the network level. We recommended strongly that future networks be clearer in reporting performance, as well as their positive and negative experiences. All implemented energy-efficiency activities should be measured thoroughly. Thus, the effect of participation can lead to a greater commitment and more elaborate knowledge and experience exchange because tangible results are easier to communicate among participants, as well as externally.

It was not within the scope of this study to set guidelines for establishing and conducting an energy-efficiency network. Rather, the aim was to highlight suggestions for improvements based on the lessons learned. The IEEN model applied in the German context, where IEENs have been applied the most, is presented in [23]. Partly based on the German model, a more general theoretical model for IEEN management can be found in a related research [63], where the concept of IEENs is related to theories on learning capability.

Participation in IEENs has long-term effects. The process requires commitment and continuous work. Thus, to achieve significant energy savings in SMEs, there is a need to step aside from project-based energy-related activities and introduce energy work into the dayto-day activities of SMEs. With this in mind, energy-efficiency networks can possibly enroot energy efficiency in corporate culture and make energy efficiency a strategic organizational issue that plays an important role in the corporate decision-making process.

\section{Acknowledgements}

We acknowledge the Swedish Energy Agency for funding this research proj ect. Also, we thank the respondents for taking the time to reply to our questions.

\section{References}

[1] IPCC, 2014. Climate Change 2014: Synthesis Report, Switzerland: Intergovernmental Panel on Climate Change.

[2] Shipley, A.M., Elliot, R.E., 2001. Energy efficiency programs for small and medium sized industry. ACEEE Summer Study, 183-196.

[3] SCB, 2010. Statistics Sweden: Energy end use in small and medium-sized industrial enterprises. Accessed December 31, 2013, from IPCC's Web site: http:/ / www.scb.se.

*Corresponding author: S. Paramonova, mob.: +46760622655, e-mail: svetlana.paramonova@liu.se 
[4] Sorrell, S., O’Malley, E., Schleich, J., Scott, S. 2004. The economics of energy efficiency: barriers to cost-effective investment, Edward Elgar Publishing.

[5] Andersson, S.T., Newell, R.G., 2004. Information programs for technology adoption: The case of energy-efficiency audits. Resource and Energy Economics 26, 17-50.

[6] Fleiter, T., Schleich, J., Ravivanpong, P., 2012. Adoption of energy-efficiency measures in SMEs-An empirical analysis based on energy audit data from Germany. Energy Policy 51, 863-875.

[7] Rohdin, P., Thollander, P., 2006. Barriers to and driving force for energy efficiency in the non-energy intensive manufacturing industry in Sweden. Energy 31, 1836-1844.

[8] Shi, H., Peng, S., Liu, Y., Zhong, P., 2008. Barriers to the implementation of cleaner production in Chinese SMEs: Government, industry and expert stakeholders' perspectives. J ournal of Cleaner Production 16, 842-852.

[9] Thollander, P., Danestig, M., Rhodin, P., 2007. Energy policies for increased industrial energy efficiency: Evaluation of a local energy programme for manufacturing SMEs. Energy Policy 35 (11), 5774-5783.

[10] Trianni, A., Cagno, E., 2012. Dealing with barriers to energy efficiency and SMEs: Some empirical evidences. Energy 37, 494-504.

[11] Trianni, A., Cagno, E., Worrell, E., 2013a. Innovation and adoption of energy efficient technologies: An exploratory analysis of Italian primary manufacturing SMEs. Energy Policy 61, 430-440.

[12] Trianni, A., Cagno, E., Worrell, E., Pugliese, G., 2013b. Empirical investigation of energy efficiency barriers in Italian manufacturing SMEs. Energy 49, 444-458.

[13] Cooremans, C., 2007. Strategic fit of energy efficiency (Strategic and cultural dimensions of energy-efficiency investments). ECEEE 2007 Summer Study Proceedings. Saving Energy-J ust Do It! 73-82.

[14] Thollander, P., Ottosson, M., 2010. Energy management practices in Swedish energyintensive industries. J ournal of Cleaner Production 18 (12), 1125-1133.

[15] J ochem, E., Gruber, E., 2007. Local learning networks on energy efficiency in industry-Successful initiative in Germany. Applied Energy 84, 806-816.

*Corresponding author: S. Paramonova, mob.: +46760622655, e-mail: svetlana.paramonova@liu.se 
[16] Koewener, D., Nabitz, L., Mielicke, U., Idrissova, F., 2014. Learning energy efficiency networks for companies-Saving potentials, realization and dissemination. ECEEE Industrial Summer Study Proceedings, 91-100.

[17] J ones, T., Verdict, M., 1995. Understanding energy efficiency investment decisions of smaller manufacturers: Energy efficiency industry roundtables. Alliance to Save Energy (U.S. ), United States. Department of Energy. Office of Energy Efficiency and Renewable Energy. Office of Industrial Technologies.

[18] Cooremans, C., 2011. Investment in energy efficiency: Do the characteristics of investments matter? ECEEE 2011 Summer Study Proceedings. Energy efficiency first: The foundation of a low-carbon society, 171-182.

[19] Edgren, J ., Skärvad, P.-H., 2010. Network organizations (Nätverksorganisationer). 1:1 red. Malmö: Liber AB [In Swedish].

[20] Svensson, L., J akobsson, E., Aberg, C., 2001. The strength of the development in networks-About learning among organizations (Utvecklingskrafteninätverk- om lärandemellanföretag). Stockholm: Santerusförlag [In Swedish].

[21] Lundberg, H., 2008. Geographical proximity effects and regional strategic networks. Department of Business Studies, Uppsala University.

[22] Elmhester, K., 2008. Small enterprises in strategic networks-How is a particular company’s development affected? (Små företag i strategiska nätverk - hur påverkas det enskilda företagets utveckling), Linköping: Linköping University [In Swedish].

[23] Koewener, D., Mielicke, U., J ochem, E., 2011. Energy efficiency networks for companies-Concept, achievements and prospects, Karlsruhe, Germany: The foundation of a low-carbon society.

[24] Klugman, S., Karlsson, M., Moshfegh, B., 2007. A Scandinavian chemical wood pulp mill. Part 1. Energy audit aiming at efficiency measures. Applied Energy 84 (3), 326-339.

[25] Li, Y., Li, J., Qiu, Q., Xu, Y., 2010. Energy auditing and energy conservation potential for glass works. Applied Energy 87 (8), 2438-2446.

[26] Thollander, P., Karlsson, M., Söderström, M., Creutz, D., 2005. Reducing industrial energy costs through energy efficiency measures in a liberalized European electricity market-Case study of a Swedish iron foundry. Applied Energy 81 (2), 115-126.

*Corresponding author: S. Paramonova, mob.: +46760622655, e-mail: svetlana. paramonova@liu.se 
[27] Agüero, J ., Rodríguez, F., Giménez, A., 2013. Energy management based on productiveness concept. Renewable \& Sustainable Energy Reviews 22, 92-100.

[28] Brunke, J.-C., J ohansson, M., Thollander, P., 2014. Empirical investigation of barriers and drivers to the adoption of energy conservation measures, energy management practices and energy services in the Swedish iron and steel industry. J ournal of Cleaner Production 84, 509-525.

[29] Lee, D., Cheng, C., 2016. Energy savings by energy management systems: A review. Renewable \& Sustainable Energy Reviews 56, 760-777.

[30] Drumm, C., Busch, J., Dietrich, W., Eickmans, J., J upke, A., 2013. STRUCTese ${ }^{\circledR}$ Energy efficiency management for the process industry. Chemical Engineering and Processing: Process Intensification, 67, 99-110.

[31] Paulus, M., Borggrefe, F., 2011. The potential of demand-side management in energyintensive industries for electricity markets in Germany. Applied Energy 88 (2), 432-441.

[32] Rudberg, M., Waldermarsson, M., Lidestam, H., 2013. Strategic perspectives on energy management: A case study in the process industry. Applied Energy 104, 487-496.

[33] Schulze, M., Nehler, H., Ottosson, M., Thollander, P., 2015. Energy management in industry-A systematic review of previous findings and an integrative conceptual framework. J ournal of Cleaner Production. In press, available online 23 J une 2015.

[34] Fleiter, T., Worrell, E., Eichhammer, W., 2011. Barriers to energy efficiency in industrial bottom-up energy demand models-A review. Renewable \& Sustainable Energy Reviews 15 (6), 3099-3111.

[35] Sorrell, S., Schleich, J., Scott, S., O’Malley, E., Trace, F., Boede, E., Ostertag, K., Radgen, P., 2000. Reducing barriers to energy efficiency in public and private organizations. SPRU (Science and Technology Policy Research).

[36] Thollander, P., Kimura, O., Wakabayashi, M., Rohdin, P., 2015. A review of industrial energy and climate policies in J apan and Sweden with emphasis towards SMEs. Renewable \& Sustainable Energy Reviews 50, 504-512.

[37] Drivsholm, T., Petersen, P., 2012. A network initiative to promote energy efficiency in SMEs. ECEEE 2012 Summer Study Proceedings. Energy Efficiency in industry, 21-30.

*Corresponding author: S. Paramonova, mob.: +46760622655, e-mail: svetlana.paramonova@liu.se 
[38] LEEN, 2013. LEEN, learning energy efficiency networks. Accessed J une 1, 2015 from LEEN's Web site: http:/ / leen. de/ en/ leen-netzwerke/ auf-einen-blick/

[39] Altea, 2013. The Hackefors model-An instrument for energy management systems (Hackefors modellen - Ett verktyg för ledningssystem). Accessed December 31, 2013, from the Altea Website: http:// altea.se/ hackeforsmodellen/ [In Swedish].

[40] Hallinan, P.J.R., 2003. The SME battle against environmental performance - the Hackefors model in Sweden, Linköping: Industrial Economics.

[41] Ammenberg, J . B. B. H. O., 1999. J oint EMS and group certification - A cost-effective route for SMEs to achieve ISO 14 001. GMI Theme Issue: ISO 140001.

[42] Cardoso, I., Guijt, I., Franco, F., Carvalho, A., Ferreira Neto, P., 2001. Continual learning for agroforestry system design: university, NGO and farmer partnership in Minas Gerais, Brazil. Agricultural Systems 69, 235-257

[43] Halme, M., 2001. Learning for sustainable development in tourism networks. Business Strategy and the Environment 10, 100-114.

[44] Manring, S., Moore, S., 2006. Creating and managing a virtual inter-organizational learning network for greener production: a conceptual model and case study. J ournal of Cleaner Production, 14, 891-899.

[45] Atkinson, R., Flint, J ., 2001. Accessing Hidden and Hard-to-Reach Populations: Snowball Research Strategies. Guildford: University of Surrey.

[46] Söderström, M. Industrial electricity use characterized by unit processes - a tool for analysis and forecasting. In: UIE XIII congress on electricity applications proceedings, Birgmingham; J une16-20, 1996. p. 77-85.

[47] Ivner, J., Thollander, P., Paramonova, S., Svensson, A., Tuenter, G., Björkman, T., Moberg, J ., 2014. Swedish energy manager networks for energy-intensive industry as a driver for improved energy efficiency. ECEEE Industrial Summer Study Proceedings, 629635.

[48] Cronvall, B., 2013. Business start-up and business growth, NUVAB. Interview October 11, 2013.

[49] Åslund, 2013. Regional Energy Officeörebro. Interview October 8, 2013.

[50] Sundquist, S., 2013. Energy Save AB, Eskilstuna. Interview October 28, 2013. *Corresponding author: S. Paramonova, mob.: +46760622655, e-mail: svetlana.paramonova@liu.se 
[51] Ragnarsson, M. , 2013. Gävle Dala Regional Energy Office. Interview, October 10, 2013.

[52] Svensson, J ., 2013. Regional Energy Office, ÖstraGötaland. Interview October 21, 2013.

[53] Petersson, C., 2013. Regional Energy Office Norra Småland. Interview October 29, 2013.

[54] Ericsson, Ö., 2013. Regional Energy Office J ämtland County. Interview October 21, 2013.

[55] Thollander, P., Palm, J. 2012. Improving energy efficiency in industrial energy systems. An interdisciplinary perspective on barriers, energy audits, energy management, policies, and programs. Springer.

[56] Anj evall, J., 2014. Regional Energy Office J amtland. Group interview, September, 17, 2014.

[57] Holmgren, M., 2014. Regional Energy Office Norrbotten. Interview, October 21, 2014.

[58] Carlsson, P.-E., 2014. The Association of Local Authorities Västernorrland. Group interview, December 2, 2014.

[59] Ragnarsson, M., 2014. GävleDala Regional Energy Office. Group interview, October 2, 2014.

[60] Lanoie, P., Rochon-Fabien, A., 2011. Promoting Pollution Prevention in Small Business: Costs and Benefits of the "Enviroclub" Initiative. Cirano, Montreal 2011.

[61] Villa, A. (2009). A road map to the development of European SME networks: towards collaborative innovation. London: Springer-Verlag.

[62] Backlund, S., Thollander, P., Palm, J., Ottosson, M., 2012. Extending the energy efficiency gap. Energy Policy 51, 392-936.

[63] Paramonova, S., Ivner., J., Thollander., P. (2014). Outsourcing Industrial Energy Management: Industrial Energy Efficiency Networks Provided As an Energy Service. Outsourcing: Strategies, Challenges and Effects on Organizations: pp. 71-98. Nova Science Publishers, Inc.

*Corresponding author: S. Paramonova, mob.: +46760622655, e-mail: svetlana.paramonova@liu.se 